\title{
Sonochemical Synthesis of Laurate Sucrose Ester as Bio- Based Plasticizer and Bio-Additive for PVC
}

\author{
Dragomir Vassilev 1,*iD, Nadezhda Petkova ${ }^{2 \mathbb{D}}$, Milka Atanasova ${ }^{3}$, , Milena Koleva ${ }^{4}$, \\ Panteley Denev 5 (D) \\ 1 Department Mathematics, Informatics, and Natural Sciences, Technical University of Gabrovo, Gabrovo, Bulgaria; \\ dvasilev@tugab.bg (D.V.); \\ 2 Department Organic and Inorganic Chemistry, University of Food Technologies, Plovdiv, Bulgaria; \\ petkovanadejda@abv.bg (N.P.); \\ 3 Department Technical Mechanic, Technical University of Gabrovo, Gabrovo, Bulgaria, matanasova@tugab.bg (M.A.); \\ 4 Department Mathematics, Informatics, and Natural Sciences, Technical University of Gabrovo, Gabrovo, Bulgaria; \\ kolevamilena@hotmail.com (M.K.); \\ 5 Department Organic and Inorganic Chemistry, University of Food Technologies, Plovdiv, Bulgaria; denev57@abv.bg \\ (P.D.); \\ * Correspondence: dvasilev@tugab.bg (D.V);
}

Scopus Author ID 57127984800

Received: 2.10.2021; Revised: 2.11.2021; Accepted: 6.11.2021; Published: 24.11.2021

Abstract: The present study shows the results obtained in the ultrasonic synthesis of sucrose esters with lauric acid, the identification of products, and the study of their possible use as bio-additives with a plasticizing effect in the processing of plastics. Fourier transform infrared spectroscopy (FTIR) and NMR $\left({ }^{1} \mathrm{H}\right.$ and ${ }^{13} \mathrm{C}$ NMR) were used to identify the synthesized esters. The plasticizing effect of sucrose laurate was assessed by determining the glass transition temperature of thin polyvinyl chloride films by differential scanning calorimetry (DSC). The results show a decrease in the glass transition temperature with an increase in the ester concentration in the polymer, which confirms the plasticizing effect of the obtained esters.

Keywords: sonochemical synthesis; laurate; sucrose; ester; bio-based plasticizer.

(C) 2021 by the authors. This article is an open-access article distributed under the terms and conditions of the Creative Commons Attribution (CC BY) license (https://creativecommons.org/licenses/by/4.0/).

\section{Introduction}

Ever-expanding resource consumption and high environmental requirements imply the search for alternative, more efficient, eco-friendly synthesis methods, as well as the reduction and recovery of industrial waste [1-5]. Various approaches are applied in chemical technologies to intensify processes depending on the type and conditions of their behavior. Ultrasonic chemistry (sonochemistry) is one of the modern strands of "green chemistry" associated with the application of ultrasonic energy to chemical effects [1, 6-8]. The main advantages of sonochemistry are the use of safer chemicals, reducing energy used, and improving the selectivity of the reaction. In many cases, ultrasonic impact facilitates the course of chemical reactions, stimulating higher efficiency and effectiveness [10-12]. Sonochemistry is unique to the phenomenon of cavitation, which is currently the subject of intensive scientific research. This process is characterized by the liquid's formation, growth, and implosion of gas microbubbles [13-18]. As microbubbles break down due to cavitation, very high pressure and temperature are generated inside them. This specific energy provides the possibility of the interaction of substances in a solution [19-23]. 
A plasticizer is a substance that is added to a material to make it softer and more flexible, increase its plasticity, decrease its viscosity, or decrease friction during its manufacturing handling.

The selection of substances with a similar function shall be carried out according to criteria, including requirements for low toxicity, optimal mixability, low migration, low volatility, etc. The most commonly used plasticizers in the processing of plastics, e.g., polyvinyl chloride (PVC), are carboxylic acid esters with linear or branched aliphatic alcohols of moderate chain length.

Among the plasticizers used in the processing of polymers, phthalates have the greatest application. Their acute toxicity is very low, but the subchronic and chronic effects are significant, both phthalates and their metabolites. This requires the search for safer and, at the same time, suitable plasticizers for plastics.

The interest in sucrose esters, which are surfactants and environmental products by themselves, has attracted the attention of researchers and manufacturers because renewable, readily available, and inexpensive raw materials, such as sucrose and fats/oils, are used to prepare them. Sucroesters are non-toxic, biocompatible, and biodegradable products widely used in food technology, cosmetics, and medicine [24].

Chang et al. have shown that many conventional reactions used to obtain functional carbohydrate derivatives can be carried out by impact with ultrasound [25].

Sucrose esters of fatty acids are synthesized by transesterification of sucrose with aliphatic esters by ultrasound. Factors influencing yield, including the type and concentration of catalyst, reaction time, and pressure, were studied [13-34].

The effect of sucrose and a mixture of GLY/sorbitol has been studied, in addition to GLY, urea, and sorbitol as plasticizers of starch films [35, 36]. A similar study examined the effect of sucrose and invert sugar on the mechanical properties, hydrophilicity, and water activity of starch films [24]. In addition, the mechanical properties of sucrose, oleic acid, sorbitol, and mannitol as plasticizers for gelatin films have been studied [37].

Yin et al. examined the application of three glucose hexanoate esters, as well as their comparison with glucose pentaacetate and sucrose octaacetate, as bio-plasticizers for polyvinyl chloride [38].

The object of the study is the production by means of ultrasonic energy of the ester of sucrose with lauric acid by transesterification and examination of the possibility of applying the resulting product as a bio-additive and/or bio-plasticizer for plastics, in particular for polyvinyl chloride.

\section{Materials and Methods}

\subsection{Reagents.}

Lauric acid (Alfa Aesar), anhydrous $\mathrm{Na}_{2} \mathrm{SO}_{4}$ (Riedel-de-Hauln), concentrated sulfuric acid, $\mathrm{K}_{2} \mathrm{CO}_{3}, \mathrm{NaCl}, n$-butanol, methanol, sucrose (Chimtex).

\subsection{Methods for esters synthesis.}

Conventional synthesis: Methanol $\left(50 \mathrm{~cm}^{3}\right)$ and 0.018 mol of methyl ester of lauric acid, sucrose, and $\mathrm{K}_{2} \mathrm{CO}_{3}$ catalyst $(0.1 \mathrm{~mol})$ were placed in an Erlenmeyer flask of $100 \mathrm{~cm}^{3}$. The flask was placed in a water bath at 40 and $65^{\circ} \mathrm{C}$. The reaction temperature was controlled by using a thermostat. The progress of the reaction was monitored by thin-layer 
chromatography. After completion of the reaction (duration $120 \mathrm{~min}$ ), the solvent was distilled under a vacuum. The residue was dissolved in $25 \% \mathrm{NaCl} / \mathrm{n}$-butanol $(1: 1, \mathrm{v} / \mathrm{v})$, and a separation funnel separated the mixture. A threefold extraction with $20 \mathrm{~cm}^{3} n$-butanol was performed. Finally, the combined extracts were dried with anhydrous $\mathrm{Na}_{2} \mathrm{SO}_{4}$, and the solvent was distilled under a vacuum.

Ultrasonic synthesis: $50 \mathrm{~cm}^{3}$ of methanol and $0.018 \mathrm{~mol}$ of methyl ester of lauric acid, sucrose, and catalyst $(0.1 \mathrm{~mol})$ were placed in an Erlenmeyer flask of $100 \mathrm{~cm}^{3}$. The flask was connected to a water-cooled reflux condenser and processed in Dimoff A-2/2 (100 W, $44 \mathrm{kHz})$ ultrasonic bath at 40 and $65^{\circ} \mathrm{C}$. The reaction temperature was controlled by using a thermostat. The progress of the reaction was monitored by thin-layer chromatography. After completion of the reaction (after $60 \mathrm{~min}$ ), the solvent was distilled in vacuo. The residue was dissolved in $25 \% \mathrm{NaCl} / n$-butanol 1:1 (v/v), and a separation funnel separated the mixture. A threefold extraction with $20 \mathrm{~cm}^{3} n$-butanol was performed. The combined extracts were dried with anhydrous $\mathrm{Na}_{2} \mathrm{SO}_{4}$, and the solvent was distilled in vacuo.

\subsection{Identification of esters.}

Infrared spectroscopy: Fourier transform infrared spectroscopy (FT-IR) was used to identify and characterize the esters obtained. The spectra were recorded on a Nicolet Avatar spectrometer (Thermo Scientific, USA) in a $\mathrm{KBr}$ tablet, in the range of $4000-400 \mathrm{~cm}^{-1}$.

Nuclear magnetic resonance imaging: The NMR spectra $\left({ }^{1} \mathrm{H}\right.$ and $\left.{ }^{13} \mathrm{C}\right)$ of the synthesized esters were recorded on a Bruker spectrometer $(500 \mathrm{MHz})$ in $\mathrm{CDCl}_{3}$ solution and a standard tetramethyl silane.

\subsection{Evaluation of sucrose laurate effect on PVC properties.}

\subsubsection{Samples preparation.}

Thin PVC films (thickness $0.18-0.28 \mathrm{~mm}$ ) containing 0, 10, 20, 30, and $40 \mathrm{wt} \%$ of sucrose laurate was used to prepare the experimental samples. The specified amount of PVC was dissolved in $100 \mathrm{~cm}^{3}$ THF in a water bath at $40^{\circ} \mathrm{C}$ until the complete dissolution of the polymer. Then the above-mentioned amount of inulin acetate was added, and the mixture was stirred for $2 \mathrm{~h}$ until complete homogenization. The resulted solution was poured into a glass Petri dish and dried at room temperature in a vacuum oven for 7 days.

\subsubsection{Determination of glass transition temperature $\mathrm{T}_{\mathrm{g}}$.}

The glass transition temperature $\mathrm{T}_{\mathrm{g}}$ of the PVC-films was determined by a differential scanning calorimetry, by 204 F1 Phoenix (NETZSCH Gerdtebau GmbH) calorimeter, using Al pans (2,5-4,2 g per sample), at a heating/cooling rate of $10 \mathrm{~K} / \mathrm{min}$, in the following consequence: heating from $20^{\circ} \mathrm{C}$ to $200^{\circ} \mathrm{C}$ (first scan); cooling in liquid nitrogen from $200^{\circ} \mathrm{C}$ to $-50^{\circ} \mathrm{C}$; second heating from $-50^{\circ} \mathrm{C}$ to $200^{\circ} \mathrm{C}$ (second scan). The measurements were carried out in argon at a flow rate of $20 \mathrm{~cm}^{3} / \mathrm{min}$. The value of $T g$ for each sample was determined in the second scan as the inflection point on the thermogram by PROTEUS software.

\subsubsection{Tensile testing.}

The tensile tests were conducted by Lloyd LS1 apparatus (Lloyd Instruments, AMETEK, Inc.), equipped with pneumatic grips and NEXYGEN Plus Materials Testing 
Software, with $100 \mathrm{~mm} / \mathrm{min}$ crosshead speed determine the tensile strength, elastic modulus, and elongation at break of each sample. Nine to twelve rectangular specimens of size $5 \times 100$ $\mathrm{mm}$ and thickness $0.18-0.28 \mathrm{~mm}$ were tested, and the average value was calculated for each PVC film.

\section{Results and Discussion}

As a result of the transesterification carried out using ultrasonic energy, a significant reduction in reaction time of $120 \mathrm{~min}$ with the conventional method to $15 \mathrm{~min}$ has been achieved, while the process is carried out at room temperature instead of at $67-70{ }^{\circ} \mathrm{C}$ (for the conventional method).

\subsection{Characterization of the obtained sucrose ester.}

\subsubsection{FT-IR spectroscopy.}

In IR spectra of the resulting esters, there are areas typical of carbohydrate areas. A new strip of esters spectrum is monitored at $1734 \mathrm{~cm}^{-1}$ due to valence vibrations of the ester $(\mathrm{vC}=\mathrm{O})$. Song [40] reported a similar strip at $1720-1728 \mathrm{~cm}^{-1}$ in sucrose octanoates and the spectrum of sucrose octanoate obtained by ultrasonic synthesis [26].

In the ${ }^{1} \mathrm{H}$ NMR spectrum of sucrose esters, particularly the sucrose laurate, the following areas may be identified - 0-3.0 ppm typical of methyl and methylene proton from the acid and 3.0-6.0 ppm typical of carbohydrate proton.

The chemical offset for the protons of the methyl groups in sucrose laurate is observed at $0.99 \mathrm{ppm}$. The presence of a band for the methylene group to an ester at $2.34 \mathrm{ppm}$ is proof of the successful synthesis.

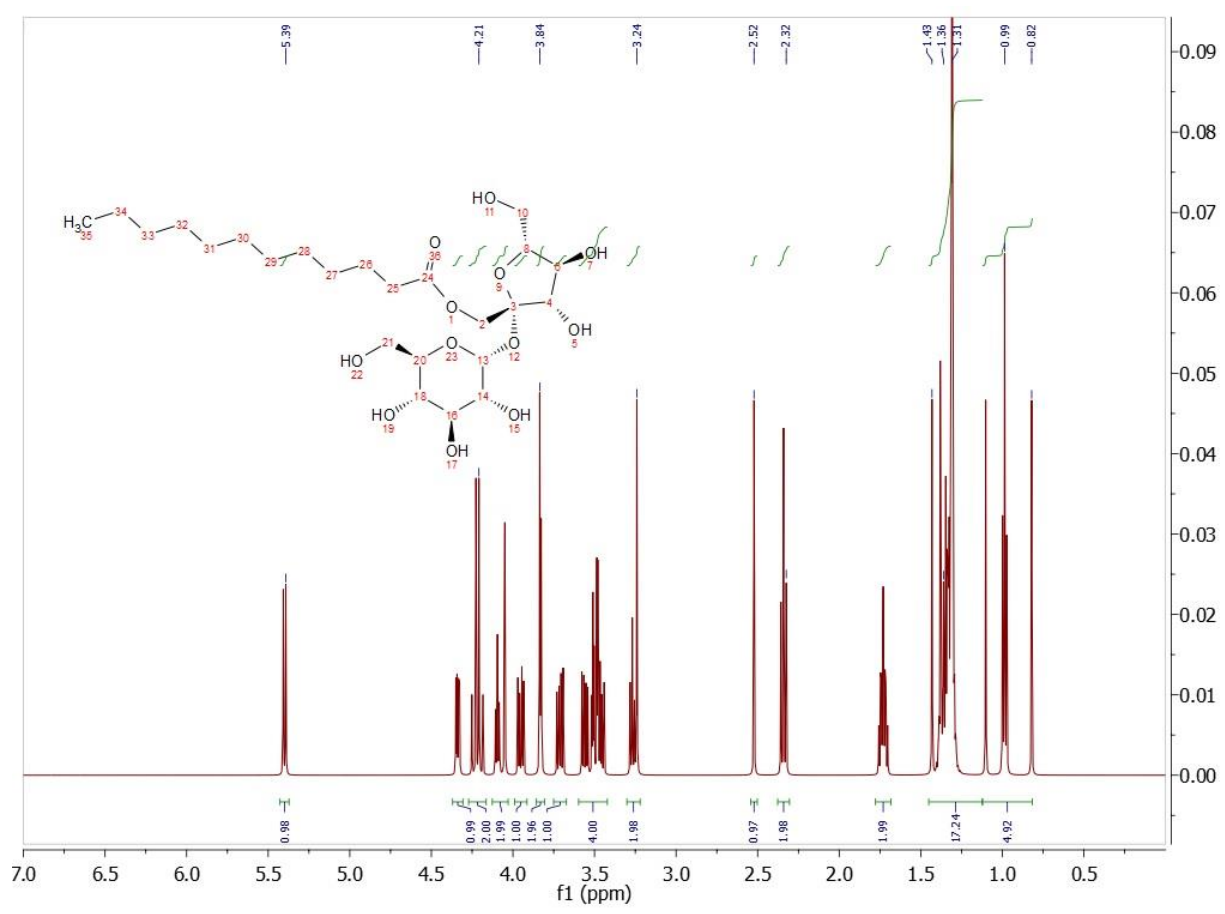

Figure 1. ${ }^{1} \mathrm{H}$ NMR spectrum of sucrose laurate.

The signals for the protons of the methylene groups in all four synthesized esters are in the range of 1.30 2.34 ppm. Glucose protons of glucopyranose are observed in the range of 3.27 5.40 ppm and glucose protons of fructofuranose at 3.83 4.09 ppm (Figure 1). 
In the ${ }^{13} \mathrm{C}$ NMR spectrum, a typical carbonyl carbon atom signal is observed at $174,6,12$ ppm. Signals for methyl carbon atoms are observed at $14.02 \mathrm{ppm}$ and for methylene ones - at 22.9-34.03 ppm.

Signals of the carbon atoms of the pyranose, respectively, of the furanose ring, are observed in the range 70.98-106.35 ppm, with carbon atoms from the pyranose ring being at the lower frequencies and for the furanose - at the higher frequency range.

\subsection{Evaluation of sucrose laurate plasticizing effect on PVC.}

\subsubsection{Differential scanning calorimetry analyses.}

The results of the DSC analysis of PVC containing inulin acetate show that the ester influences the behavior of the polymer, whereas its content increases, while the glass transition temperature lowers (Table 1). According to the existing theories on the plasticizing mechanism, the function of the polymer additives called "plasticizers" is to reduce the interaction between the polymer chains, thereby increasing the free volume in the polymer, which in turn is a prerequisite for increasing their flexibility. In this case, the quantitative measurer of the action of the plasticizer is the lowering of the polymer's glass transition temperature. The presence of inulin acetate results in a decrease of $T g$ of approximately $81{ }^{\circ} \mathrm{C}$ in pure $\mathrm{PVC}$ to approx. $56{ }^{\circ} \mathrm{C}$ in ester content of $30 \%$, it might be expected that it increases the flexibility of structural elements of the polymer and that way exhibits similar to the plasticizing effect on PVC.

Table 1. DSC analyses of PVC-containing sucrose esters.

\begin{tabular}{c|c|c|c}
\multirow{2}{*}{$\begin{array}{c}\text { Ester content, } \\
\%\end{array}$} & \multicolumn{3}{|c}{ Glass transition temperature, ${ }^{\mathbf{0}} \mathbf{C}$} \\
\cline { 2 - 4 } & $\begin{array}{c}\text { Inuline acetate } \\
{[\mathbf{1 9 ]}}\end{array}$ & $\begin{array}{c}\text { Sucrose palmitate } \\
{[\mathbf{1 8}]}\end{array}$ & Sucrose laurate \\
\hline $0 \%$ & 80.5 & 80.5 & 80.5 \\
\hline $10 \%$ & 53.5 & 73.9 & 72.8 \\
\hline $20 \%$ & 60.7 & 67.3 & 65.8 \\
\hline $30 \%$ & 56.4 & 53.2 & 52.1
\end{tabular}

3.2.2. Mechanical properties of PVC/sucrose laurate blends.

According to the existing theories on the plasticizing mechanism, the plasticizer's function is to reduce the interaction between the polymer chains, thereby increasing the free volume in the polymer, which in turn is a prerequisite for increasing their flexibility. In this case, the quantitative measurer of the action of the plasticizer is the lowering of the glass transition temperature of the polymer $\mathrm{Tg}$.

The results of the DSC analysis of PVC containing sucrose laurate show that the ester influences the behavior of the polymer, whereas its content increases while the temperature of glass transition of $\mathrm{Tg}$ lowers from approximately $81^{\circ} \mathrm{C}$ in pure $\mathrm{PVC}$ to $52.1^{\circ} \mathrm{C}$ in ester content of 30\% (Table 2), i.e., sucrose laurate has a plasticizing effect on PVC.

Similar results have been obtained using sucrose palmitate [31], inulin acetate [32] by other scientists in the experimental application of esters as plasticizers of PVC [41].

Table 2. Mechanical properties of PVC containing sucrose laurate.

\begin{tabular}{c|c|c|c|c|c|c|c|c|c}
\multirow{2}{*}{$\begin{array}{c}\text { Ester } \\
\text { content, \% }\end{array}$} & \multicolumn{3}{|c|}{ Stress at the break, MPa } & \multicolumn{3}{c|}{ Young's Modulus, MPa } & \multicolumn{3}{c}{ Elongation at Fracture, \% } \\
\cline { 2 - 10 } & $\begin{array}{c}\text { InAc } \\
{[\mathbf{3 2}]}\end{array}$ & $\begin{array}{c}\text { SucPa } \\
{[\mathbf{3 1}]}\end{array}$ & SucLa & $\begin{array}{c}\text { InAc } \\
{[\mathbf{3 2}]}\end{array}$ & $\begin{array}{c}\text { SucPa } \\
{[\mathbf{3 1}]}\end{array}$ & SucLa & $\begin{array}{c}\text { InAc } \\
{[32]}\end{array}$ & $\begin{array}{c}\text { SucPa } \\
{[31]}\end{array}$ & SucLa \\
\hline $0 \%$ & 52.4 & 52.4 & 52.4 & 1483.0 & 1483.0 & 1483.0 & 5.5 & 5.5 & 5.5 \\
\hline $10 \%$ & 48.2 & 26.0 & 24.5 & 1017.4 & 864.0 & 756.3 & 8.9 & 81.2 & 82.5
\end{tabular}




\begin{tabular}{|c|c|c|c|c|c|c|c|c|c|}
\hline \multirow[b]{2}{*}{$\begin{array}{c}\text { Ester } \\
\text { content, \% }\end{array}$} & \multicolumn{3}{|c|}{ Stress at the break, MPa } & \multicolumn{3}{|c|}{ Young's Modulus, MPa } & \multicolumn{3}{|c|}{ Elongation at Fracture, \% } \\
\hline & $\begin{array}{c}\text { InAc } \\
{[32]}\end{array}$ & $\begin{array}{c}\text { SucPa } \\
{[31]}\end{array}$ & SucLa & $\begin{array}{c}\text { InAc } \\
{[32]}\end{array}$ & $\begin{array}{c}\text { SucPa } \\
{[31]}\end{array}$ & SucLa & $\begin{array}{c}\text { InAc } \\
{[32]}\end{array}$ & $\begin{array}{c}\text { SucPa } \\
{[31]}\end{array}$ & SucLa \\
\hline $20 \%$ & 41.0 & 21.4 & 18.8 & 713.0 & 718.0 & 654.8 & 19.3 & 97.8 & 103.6 \\
\hline $30 \%$ & 39.5 & 19.5 & 17.9 & 677.8 & 620.5 & 560.6 & 22.0 & 126.8 & 135.3 \\
\hline
\end{tabular}

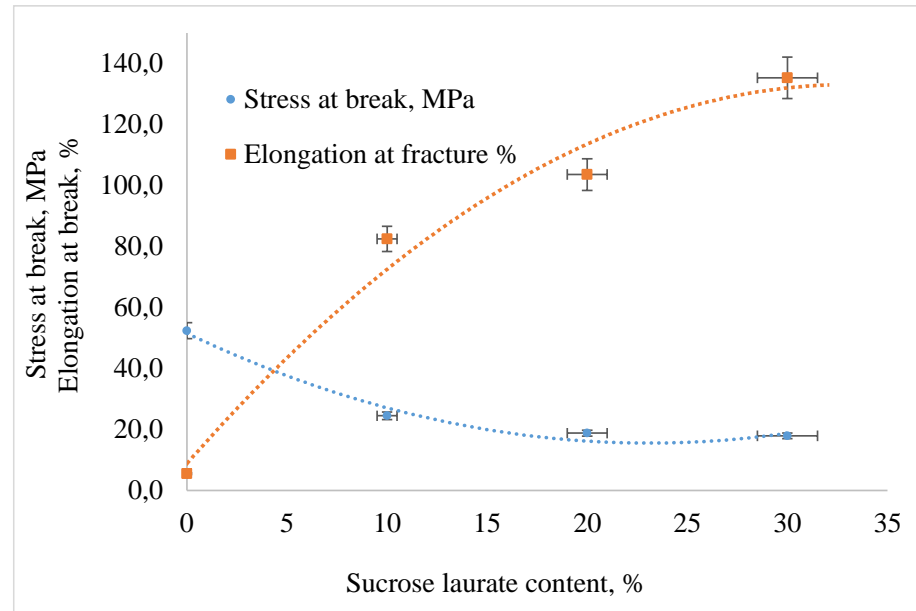

Figure 2. Mechanical properties of PVC containing sucrose laurate.

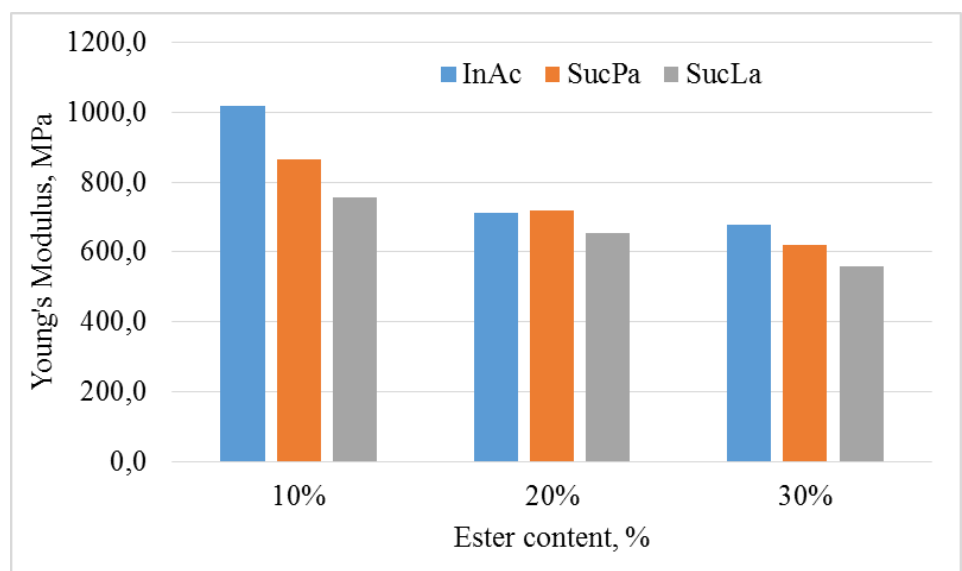

Figure 3. The elasticity modulus of PVC containing: inulin acetate (InAc), sucrose palmitate (SucPa), and laurate (SucLa) - 10, 20, and 30\%.

The increased flexibility of structural elements of the polymer as a result of the activity of the plasticizer affects its deformation behavior and strength characteristics. The extent and nature of this influence are a function of the quantity and chemical structure of the plasticizer and are usually estimated under tensile load.

The results of the tensile tests on PVC films containing sucrose laurate show that the ester content increases to 20-25\% w/w, while the elasticity modulus decreases nearly twice $1483 \mathrm{MPa}$ for non-plasticized PVC to $713 \mathrm{MPa}$ at ester content of $20 \% \mathrm{w} / \mathrm{w}$. The breaking voltage also decreases - from 52.3 MA for unplasticized PVC to $30 \mathrm{MA}$ at an ester content of $20 \% \mathrm{w} / \mathrm{w}$. The relative elongation at break increases sharply: at ester content of $20 \% \mathrm{w} / \mathrm{w}$; it is up to 4 times higher than the one of the pure PVC (Figure 2 and 3). In view of the mechanism of action of plasticizers mentioned above, these results are typical and demonstrate the plasticizing effect of sucrose laurate on PVC in the specified concentration range.

With sucrose laurate content over $20 \% \mathrm{w} / \mathrm{w}$, certain characteristics in PVC/sucrose laurate system are reported, such as the increase of breaking stress and the expected decrease 
of the relative elongation. Although the downward trend for the module is maintained, its alteration with an increase of sucrose laurate content is relatively feebly marked. That is, with sucrose laurate content over $20 \% \mathrm{w} / \mathrm{w}$, the plasticizing effect weakens. However, a certain positive effect on the strength properties of the plasticized polymer appears. It is known that the effectiveness of the plasticizer on PVC depends on the size and polarity of its molecule the ability of the small molecule of the plasticizer to penetrate the amorphous and to weaken the interaction between macromolecules is the basis of the mechanism of plasticizing. Compared to conventional PVC plasticizers such as phthalates, which are low molecular compounds, sucrose laurate molecules are significantly larger - in addition to being a longchain polysaccharide, they also contain substitutes. At low contents, ester exhibits plasticizing effect probably due to the ability of its molecules to occupy the free volume between macromolecules of the polymer, predominantly in amorphous regions. At higher contents, however, most probably due to the close contact with PVC macromolecules, molecular chains of sucrose laurate "intertwine with them" reducing their flexibility - the result is an increase in the tension and decrease of the relative elongation upon breaking of the plasticized PVC. Similar behavior has been observed in some bio-plasticizers based on palm oil used as a coplasticizer for PVC. In this case, however, the modular increase is also observed, which allows the authors to conclude the increasing enhancing effects of the test compounds.

With a view of the above, the influence of ester on PVC behavior in contents over $20 \%$ $\mathrm{w} / \mathrm{w}$ is also of interest. This, however, shall be subject to further in-depth studies. In case a similar "increasing" mechanism of action of sucrose laurate is confirmed, it could successfully be applied as a co-plasticizer in combination with other conventional PVC bio-plasticizers while contributing to the improvement of strength properties of the polymer.

\section{Conclusions}

An experimental process of transesterification of sucrose has been carried out. The product resulting from the synthesis has been identified as sucrose laurate using highly sensitive spectral methods. US impact sharply accelerates the synthesis process without affecting the chemical composition and structure of the resulting products. The results of the studies make it possible to conclude that ultrasonic transesterification is an applicable method for intensifying the synthesis process of esters.

The applicability of sucrose laurate as PVC bio-plasticizer has been examined. The influence of the ester on the temperature of glass transition $\mathrm{Tg}$ of PVC in contents of 0-40\% w/w was estimated by the DSC method. It has been found out that the increase of its quantity results in the decrease of polymer $T g$, i.e., the flexibility of macromolecules increases which is a prerequisite for higher deformability. It is proved by studies on the influence of ester over PVC behavior under tensile load. Contents of sucrose laurate of up to $20 \% \mathrm{w} / \mathrm{w}$ have been found to reduce the tension, increase the relative elongation upon breaking, and reduce the module. This supports the conclusion that inulin acetate shows plasticizing effect within this concentration range. The polymer's more specific behavior has been observed in ester contents over $20 \% \mathrm{w} / \mathrm{w}$, namely increase of the tension and decrease of the relative elongation upon breakage along with insignificant alteration of the module.

The results obtained at this stage of the study allow for a conclusion that synthesized sucrose laurate is applicable as a bio-plasticizer for PVC in contents of up to $20-25 \%$ w/w. Further studies must be carried out in order to establish the mechanism of activity of the ester in higher contents with a view of application extension. 


\section{Funding}

This research was funded by the Technical University of Gabrovo, grant number 2106C/2021.

\section{Conflicts of Interest}

The authors declare no conflict of interest.

\section{References}

1. Mason, T.; Peters, D. Practical sonochemistry. Horwood Publishing Limited 2011, https://www.elsevier.com/books/practical-sonochemistry/mason/978-1-898563-83-9.

2. Shendabadi, A.R.; Tebyanian, H.; Zare, R.; Dekamin, M.G.; Kooshki, H.; Rashidiani, J. 1, 3, 5-Tris (2hydroxyethyl) Isocyanurate Functionalized SBA-15 (THEIC-SBA-15): as a Novel Heterogeneous NanoCatalyst for the One-Pot Three-Component Synthesis of Tetrahydrobenzo b Pyrans in Water. Biointerface Research in Applied Chemistry 2020, 10, 6706-6717, https://doi.org/10.33263/briac106.67066717.

3. Shams, A.; Mortazavi, A.; Khosravi-Darani, K.; Bahmaei, M.; Reihani, S.F.S.; Tripathy, A.D. Effects of liposomal natural and synthetic antioxidants on oxidative stability of soybean oil. Biointerface Research in Applied Chemistry 2019, 9, 3963-3968, https://doi.org/10.33263/briac93.963968.

4. Smutzer, G.; Cherian, S.; Patel, D.; Lee, B.S.; Lee, K.; Sotelo, A.R.; Mitchell, K.-.W. A formulation for suppressing bitter taste in the human oral cavity. Physiol. Behav., 2020, 22, 113129, https://doi.org/10.1016/j.physbeh.2020.113129.

5. Teng, Y.; Stewart, SG.; Hai, Y.W.; Li, X.; Banwell, M.G.; Lan, P. Sucrose fatty acid esters: synthesis, emulsifying capacities, biological activities and structure-property profiles. Crit Rev Food Sci Nutr 2020, 4, 1-21, https://doi.org/10.1080/10408398.2020.1798346.

6. Vargas, J.; Ortega J.; Metzker G.; Larrahondo J.; Boscolo, M. Natural sucrose esters: Perspectives on the chemical and physiological use of an under investigated chemical class of compounds. Phytochem 2020, 177, 112433, https://doi.org/10.1016/j.phytochem.2020.112433.

7. Long, N.T.T.; Boi, V.N.; Cuong, D.X.; Diep, T.T.; Minh, N.T.; Bich, L.N. Effect of the growth time on the content of inulin, polyphenol, flavonoids, total sugar, and minerals, and antioxidant activity of vietnamese dangshen roots codonopsis janica. Int. J. Pharm. Sci. Res., 2020, 12, 1849-1856, https://doi.org.10.31838/ijpr/2020.12.03.031.

8. Deng R.; Li W.; Berhow M.A.; Jander G.; Zhou S. Phenolic sucrose esters: evolution, regulation, biosynthesis, and biological functions. Plant Mol Biol. 2021, 30, https://doi.org/10.1007/s11103-021-01142$\mathrm{y}$.

9. Nieto, S.; Villa R.; Donaire A.; Lozano P. Ultrasound-assisted enzymatic synthesis of xylitol fatty acid esters in solvent-free conditions. Ultrason Sonochem, 2021, 75, 105606, https://doi.org/10.1016/j.ultsonch.2021.105606.

10. Nguyen, L.; Le T.; Duong C.; Vo Ch.; Duus F.; Luu Th. Direct synthesis of sulfinic esters via ultrasound accelerated tandem reaction of thiols and alcohols with N-bromosuccinimide. J. Sulphur Chem. 2021, 42, 5 , 519-528, https://doi.org/10.1080/17415993.2021.1928669.

11. Low, D.; Mahendra, C.; Supramaniam, J.; Tan, L.; Lee, L.; Manickam, S.; Goh, B.; Tan, K.; Tang, S. Ultrasound-enhanced biosynthesis of uniform $\mathrm{ZnO}$ nanorice using Swietenia macrophylla seed extract and its in vitro anticancer activity. Nanotechnology Reviews 2021, 10, 572-585, https://doi.org/10.1515/ntrev2021-0044.

12. Moentamaria, D.; Rulianah, S.; Chumaidi, A.; Bilghis A.; Romadoni, R. Enhancement in synthesis of citronellyl laurate flavour by combined effect of ultrasound and immobilized lipase as heterogeneous biocatalyst. IOP Conference Series. Materials Science and Engineering, 2021, 1073, https://doi.org/10.1088/1757-899X/1073/1/012001.

13. Vargas, J.; Ortega J.; Correia dos Santos M.; Gomes E.; Boscolo, M. A new synthetic methodology for pyridinic sucrose esters and their antibacterial effects against Gram-positive and Gram-negative strains. Carbohydr. Res. 2020, 489, 107957, https://doi.org/10.1016/j.carres.2020.107957.

14. Lara-Cerón, J.; Jiménez-Pérez V.; Molina-Paredes, A.; Ochoa M.; Sábio R.; Amaral A.; Silva R.; Ribeiro S.; Barud H.; Muñoz-Flores B. Ultrasound-assisted synthesis of organotin compounds and their application as 
luminescent dye in silk fibroin scaffolds. Inorganica Chim. Acta 2020, 505, 119490, https://doi.org/10.1016/j.ica.2020.119490.

15. Sian H.; Abdullah H.; Kan S.; Chia P. Chapter 10 - Microwave- and ultrasound-assisted heterocyclics synthesis in aqueous media. Green Sustainable Process for Chemical and Environmental Engineering and Science. Elsevier 2020, 319-355, https://doi.org/10.1016/B978-0-12-819542-0.00010-5.

16. Zhang, Y.; Dai, Y.; Hou, H.; Li, X.; Dong, H.; Wang, W.; Zhang H. Ultrasound-assisted preparation of octenyl succinic anhydride modified starch and its influence mechanism on the quality. Food Chem. 2020, 5 , 100077, https://doi.org/10.1016/j.fochx.2020.100077.

17. Bedi, P.; Pramanik, G.; Pramanik, T. Microwave assisted green synthesis of pharmaceutically potent benzoxanthone analogues employing biodegradable oxalic acid as ecofriendly catalyst. Biointerface Res. Appl. Chem. 2019, 9, 4311-4316, https://doi.org/10.33263/briac95.311316.

18. Elazab, H.A.; El-Idreesy, T.T. Optimization of the catalytic performance of $\mathrm{Pd} / \mathrm{Fe} 3 \mathrm{O} 4$ nanoparticles prepared via microwave-assisted synthesis for pharmaceutical and catalysis applications. Biointerface Res. Appl. Chem. 2019, 9, 3794-3799, https://doi.org/10.33263/briac91.794799.

19. Tolaba, A.G.; Pellizaro, T.A.G.; Rodriguez-Chanfrau, J.E.; Guastaldi, A.C. Statistical evaluation of the effect of ultrasound on the synthesis of calcium phosphates. Biointerface Research in Applied Chemistry 2019, 9, 4345-4348, https://doi.org/10.33263/briac95345348.

20. Zhang, Q.Y.; Zhao, L.; Deng, T.L.; Zhang, Y.T.; Li, H. Catalytic production of biodiesel from esterification of lauric acid over a solid acid hybrid. Biointerface Res. Appl. Chem.2020, 10, 5760-5764, https://doi.org/10.33263/briac104.760764.

21. Farrage, N.M.; Oraby, A.H.; Abdelrazek, E.M.M.; Atta, D. Synthesis, characterization of Ag@PANI coreshell nanostructures using solid state polymerization method. Biointerface Res. Appl. Chem. 2019, 9, 39343941, https://doi.org/10.33263/briac93.934941.

22. Ullah, F.; Javed, F.; Khan, A.N.; Kudus, M.H.A.; Jamila, N.; Minhaz, A.; Akil, H.M. Synthesis and surface modification of chitosan built nanohydrogel with antiviral and antimicrobial agent for controlled drug delivery. Biointerface Res. Appl. Chem. 2019, 9, 4439-4445, https://doi.org/10.33263/briac96.439445.

23. Elazab, H.A.; El-Idreesy, T.T. Optimization of the catalytic performance of $\mathrm{Pd} / \mathrm{Fe} 3 \mathrm{O} 4$ nanoparticles prepared via microwave-assisted synthesis for pharmaceutical and catalysis applications. Biointerface Res. Appl. Chem., 2019, 9, 3794-3799, https://doi.org/10.33263/briac91.794799.

24. Baker, I.; Willing R.; Furlong D.; Grieser F.; Drummond C. Sugar Fatty Acid Ester Surfactants: Biodegradation Pathways. J Surfactants Deterg 2000, 3, 13-27, https://doi.org/10.1007/s11743-000-0108-1.

25. Deng, Sh.; Gangadharmath, U.; Chang, Ch. Sonochemistry: A Powerful Way of Enhancing the Efficiency of Carbohydrate Synthesis. J. Org. Chem., 2006, 71, 5179-5185, https://doi.org/10.1021/jo060374w.

26. Dan, H.; Kang-Rong, Zh.; Wen-Feng, S. Ultrasonic Synthesis, Characteristic and Application of Sucrose Octanoate. Chin. J. Org. Chem. 2009, 29, 1951-1955, https://www.researchgate.net/publication/281875075_Ultrasonic_Synthesis_Characteristic_and_Applicatio n_of_Sucrose_Octanoate.

27. Yongshi, Xu.; Fangxue H.; Dacheng Li, Hong L.; Xizhu Y. Synthesis of sucrose laurate via transesterification under ultrasonic irradiation. Chem Eng Prog., 2013, 32, 1656-1660, http://hgjz.cip.com.cn/EN/abstract/abstract4788.shtml.

28. Zhong, K.; Dan H.; Wen-feng Z.; Wei-dong G. Ultrasonic synthesis and characterization of sucrose octanoate. J. Chem. Res. 2009, 20, 65-68, http://sioc-journal.cn/Jwk_yjhx/EN/Y2009/V29/I12/1951.

29. Yuyun, Lu, Yan R.; Ma X.; Wang Y. Synthesis and characterization of raffinose fatty acid monoesters under ultrasonic irradiation. Eur. Food Res. Technol., 2013 , 237, 237-244, https://doi.org/10.1007/s00217-0131985-y.

30. Petkova, N.; Tumbarski Y.; Ivanov I. Denev P. Design of inulin acetates with potential antimicrobial activity. Bulg. J. Vet. Med. 2017, 20, 13-17, http://uni-sz.bg/truni11/wpcontent/uploads/vmf/file/02\%20Tumbarski\%202.pdf.

31. Vassilev, D.; Petkova N.; Koleva M.; Denev P. Ultrasound-Assisted Synthesis of Sucrose and Fructooligosaccharides Esters as Bio-Plasticizers. J. Renew. Mater. 2016, 4, 24-30. https://doi.org/10.7569/JRM.2015.634125.

32. Vassilev, D.; Petkova, N.; Koleva M.; Denev P. Microwave synthesis of inulin acetate as potential bio-based additive for poly(vinyl chloride). J. Renew. Mater. 2018, 6, 707-714, https://doi.org/10.32604/JRM.2018.00015. 
33. Vassilev, D.; Petkova, N.; Tumbarski, Y.; Koleva, M., Denev, P. Application of the principles of "Green Chemistry" for the synthesis of 10-undecylenic aliphatic esters with antimicrobial activity. J. Renew. Mater. 2020, 8, 675-686, https://doi.org/10.32604/jrm.2020.09279.

34. Vassilev, D.; Petkova N.; Koleva M.; Denev P. Optimization of ultrasound synthesis of sucrose esters by selection of a suitable catalyst and reaction conditions. Journal of Chemical Technology and Metallurgy 2021, 56, 268-274, https://dl.uctm.edu/journal/node/j2021-2/2_19-232p268-274.pdf.

35. Galdeano, M.; Grossmann, M.; Mali,S.; Bello-Perez, LA.; Garcha, M.A.; Zamudio-Flores, P.B. Effects of production process and plasticizers on stability of films and sheets of oat starch. Mater Sci Eng C 2009, 29, 492-498, https://doi.org/10.1016/j.msec.2008.08.031.

36. Galdeano, M.; Mali S.; G.M.V.E.; Yamashita F.; García M.A. Effects of plasticizers on the properties of oat starch films. Mater Sci Eng C 2009, 29, 532-538, https://doi.org/10.1016/j.msec.2008.09.034.

37. Veiga-Santos,P; Oliveira,L.M.; Cereda, M.P.; Scamparini, A.R.P. Sucrose and inverted sugar as plasticizer. Effect on cassava starch-gelatin film mechanical properties, hydrophilicity and water activity. Food Chem 2007, 103, 2, 255-262, https://doi.org/10.1016/j.foodchem.2006.07.048.

38. Yang X.; Cao N.; Fu Y. Effects of various plasticizers on mechanical and water vapor barrier properties of gelatin films. Food Hydrocol 2009, 23, 729-35, https://doi.org/10.1016/j.foodhyd.2008.07.017.

39. Yin, B.; Aminlashgari N.; Yang X.; Hakkarainen M. Glucose esters as biobased PVC plasticizers. Eur. Polym. J 2014, 58, 34-40, https://doi.org/10.1016/j.eurpolymj.2014.06.008.

40. Song Z.; Li S.; Chen X. Synthesis of insecticidal sucrose esters. For. Stud. China 2006, 8, 26-29, https://doi.org/10.1007/s11632-006-0019-2.

41. Rahmah, M.; Nurazzi N.; Nordyana A.; Anas S. Effect of epoxidised soybean oil loading as plasticiser on physical, mechanical and thermal properties of polyvinylchloride. IOP Conf. Ser.: Mater. Sci. Eng. 2017, 223, 012048, https://doi.org/10.1088/1757-899X/223/1/012048. 